\title{
ANÁLISE DA INFLUÊNCIA DA ACIDEZ E DA TEMPERATURA DO SISTEMA SOBRE REMOÇÃO DE CROMO TOTAL UTILIZANDO RESINA MISTA.
}

\author{
M. A. BARROS ${ }^{1}$, T. S. CARMO ${ }^{2}$ e M. R. FRANCO JUNIOR ${ }^{3}$ \\ ${ }^{1}$ Universidade Federal de Uberlândia, Faculdade de Engenharia Química \\ ${ }^{2}$ Universidade Federal de Uberlândia, Faculdade de Engenharia Química \\ ${ }^{3}$ Universidade Federal de Uberlândia, Faculdade Engenharia Química \\ E-mail para contato: cidabarros_154@yahoo.com.br
}

\begin{abstract}
RESUMO - A rápida industrialização levou a um aumento no uso de metais pesados, ao longo das últimas décadas, e resultou, inevitavelmente, em um fluxo aumentado de substâncias metálicas no ambiente aquático. Esta industrialização pela qual vem passando o mundo é a principal causa de contaminação de águas, solos e atmosfera. O avanço da tecnologia, aliado ao capitalismo tem uma consequiência implacável: o desequilíbrio do ecossistema. Dentre os metais, mais utilizados, pode-se salientar o cromo, que, peculiarmente, se apresenta de forma tri e hexavalente. Deste modo, este trabalho visa avaliar o efeito da temperatura, $\mathrm{pH}$, bem como da massa de adsorvente, na remoção de cromo utilizando uma resina mista comercial com tamanho de partícula fixo. A influência do $\mathrm{pH}$ foi testada à temperatura $25^{\circ} \mathrm{C}$ variando-se o $\mathrm{pH}$ da mistura de 2,0 a 10,0 . Ademais, o efeito térmico, ou seja, de variação da temperatura do meio foi verificado através de estudos isotérmicos, com processos batelada, empregando-se célula de equilíbrio operando a $25^{\circ} \mathrm{C}, 35^{\circ} \mathrm{C}$ e $45^{\circ} \mathrm{C}$, em três concentrações iniciais de cromo que variaram de $10-50 \mathrm{mg} / \mathrm{L}$. Os resultados obtidos mostram, claramente, a importância dos parâmetros estudados no processo de remoção do íon cromo, sendo que o pH em torno de 2,0 e a temperatura de $25^{\circ} \mathrm{C}$ foram os mais apropriados ao processo de adsorção do cromo utilizando a Resina Mista.
\end{abstract}

\section{INTRODUÇÃO}

Poluição por metais pesados tem sido agravado por todo o mundo com a expansão das atividades industriais e humanas (Park, 2006). Cromo e seus compostos, amplamente utilizado em várias indústrias e processos químicos, geram uma grande quantidade de efluentes tóxicos contendo o metal. Ao contrário de outros íons inorgânicos, o cromo não é degradável e acumula-se nos organismos através da cadeia alimentar. Entre os seus vários estados de oxidação, o cromo tri e hexavalente são comumente encontrados nos efluentes de resíduos industriais, sendo o $\mathrm{Cr}$ (VI) considerado carcinogênico pela Organização Mundial de Saúde, causando vários tipos 
de doenças em seres humanos tais como, convulsões, danos da pele e órgãos, e até mesmo a morte em grande dosagens (Gooloka, 1995; Kaufaman, 1970).

A remoção dos metais pesados presentes em efluentes industriais pode ser feita por meio de diversos processos, tais como precipitação por via química, osmose reversa, adsorção em carvão ativado ou alumina e oxi-redução. As técnicas tradicionais de tratamento envolvem alto custo e entrada contínua de produtos químicos, gerando assim um processo impraticável e antieconômico além de causar mais danos ambientais. Por isso, são necessárias técnicas fáceis, eficazes, econômicas e ecológicas para o tratamento de efluentes (Padmavathy et al., 2002). Alguns exemplos dessas técnicas são: ultrafiltração; remoção por biomassa de plantas aquáticas; utilização de matéria orgânica morta; emprego de microrganismos; precipitação de metais por solos incinerados; precipitação e flotação de sulfetos e resinas.

As resinas são muito utilizadas nas indústrias para a remoção de íons em água potável ou em águas de caldeira e na purificação de substâncias orgânicas e inorgânicas. Entretanto, a utilização desse material no tratamento de efluentes contendo metais pesados é economicamente inviável (Pal e Banat, 2014; Liu et al., 2012). O objetivo deste trabalho foi investigar a influência da acidez e da temperatura visando o tratamento de efluentes aquosos contaminados por metais, especialmente o Cromo, utilizando-se da Resina Mista.

\section{MATERIAIS E MÉTODOS}

As resinas utilizadas foram Resina Mista Purolite e Resina Catiônica Purolite. Os experimentos, deste trabalho, foram realizados utilizando-se, como fonte de cromo, soluções aquosas preparadas com dicromato de potássio $\left(\mathrm{K}_{2} \mathrm{Cr}_{2} \mathrm{O}_{7}\right)$, marca Labsynth 99\%,. Este reagente era pesado e dissolvido, em água destilada, para se obter a Solução Estoque de Cromo (SEC) em uma concentração de $1.000 \mathrm{mg} / \mathrm{L}$ conforme metodologia descrita no APHA (1989) e depois diluída para as concentrações desejadas.

Todos os experimentos foram realizados em batelada, utilizando células de vidro encamisadas de $100 \mathrm{~mL}$ cada, ligadas a um banho termostático $\left( \pm 0,1^{\circ} \mathrm{C}\right)$. $\mathrm{O}$ sistema composto de aproximadamente $90 \mathrm{~mL}$ de solução do metal e adsorvente $(5,0 \mathrm{~g} / \mathrm{L})$ foi mantido, sob agitação, por agitadores magnéticos, a uma velocidade de $175 \mathrm{rpm}$. Amostras de 3,0 mL eram coletadas com o auxílio de pipeta (RONI-ALZI) com precisão de $\pm 0,1 \mathrm{~mL}$ e analisadas no equipamento de absorção atômica da marca Shimadzu e modelo 7000 (AA-7000).

\subsection{Influência do pH}

$\mathrm{O}$ efeito do $\mathrm{pH}$ na adsorção dos metais foi testado em sistemas análogos ao anterior, com concentração de $10,0 \mathrm{mg} / \mathrm{L}$ do metal e temperatura de $25^{\circ} \mathrm{C}$, o pH foi ajustado para 2,0; 5,5; 8,0 e 10,0; pela adição de soluções $0,1 \mathrm{~mol} / \mathrm{L}$ de $\mathrm{NaOH}$ ou $\mathrm{HCl}$. 


\subsection{Teste cinético e Influência da temperatura}

Adotou-se um tempo de experimento de 180 minutos, para avaliação da cinética de adsorção do cromo utilizando temperaturas constantes de $25^{\circ} \mathrm{C} .35^{\circ} \mathrm{C}$ e $45^{\circ} \mathrm{C}$, para os experimentos. Amostragens eram feitas, em intervalos de 5 minutos, nos primeiros quatro pontos, a cada 10 minutos no quinto e sexto pontos, 20 minutos no sétimo ponto e 30 minutos nos demais pontos, sendo no total 11 pontos. A variação no tempo ocorreu devido a pouca variação nos valores experimentais, indicando assim o equilíbrio. A quantidade de cromo adsorvida pela resina (q) em cada tempo foi calculada utilizandose a Equação (1):

$$
q=\frac{V\left(C_{0}-C_{t}\right)}{m}
$$

em que $C o$ é a concentração inicial da solução de cromo $(\mathrm{t}=0), C_{t}$ é a concentração da solução de cromo no tempo $t, V$ é o volume da solução de cromo no frasco, e $m$ é a massa do adsorvente (base seca).

\subsection{Isotermas de adsorção}

Segundo McCabe et al. (2001), a isoterma de adsorção representa a relação de equilíbrio entre a concentração de um componente na fase fluida e sua concentração nas partículas de adsorvente, em uma determinada temperatura. A quantidade de adsorbato presente no sólido é expressa por massa adsorvida por unidade de massa do adsorvente original. Neste trabalho o modelo utilizado foi a Isoterma de Henry. A isoterma de Henry, representada pela Equação 2.

$$
q_{e}=k C_{e}
$$

Em que $k$ representa a constante de Henry, $q_{e}$ a concentração de adsorbato na superfície do adsorvente e $C_{e}$ a concentração de equilíbrio do adsorbato na fase fluida.

\section{RESULTADOS E DISCUSSÃO}

\subsection{Influência do pH}

A influência do pH no processo de adsorção do cromo por Resina Mista Purolite pode ser observado na Figura 3.1. 


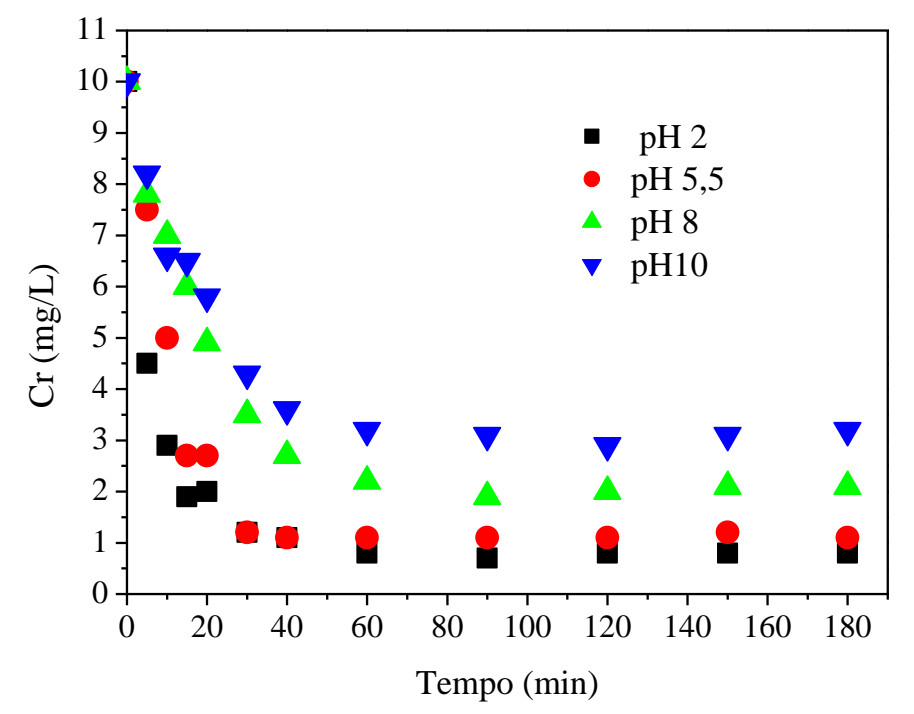

Figura 3.1- Variação da concentração do íon cromo em função do pH. ( $\mathrm{T}=25^{\circ} \mathrm{C}$; [Cr] $=10,0 \mathrm{mg} / \mathrm{L} ;[$ resina mista $]=5,0 \mathrm{~g} / \mathrm{L})$.

Os resultados apresentados mostram a importância do $\mathrm{pH}$ no processo de remoção do íon cromo. $\mathrm{O}$ pH afeta a solubilidade dos metais e a ionização dos grupos funcionais presentes na superfície, a sua influência é devida a uma competição entre os íons do metal e os íons H+ presentes em solução pelos sítios ativos da superfície do material adsorvente (Chubar et al., 2004 , Ozdemir, 2004 e Selatnnia et al., 2004).

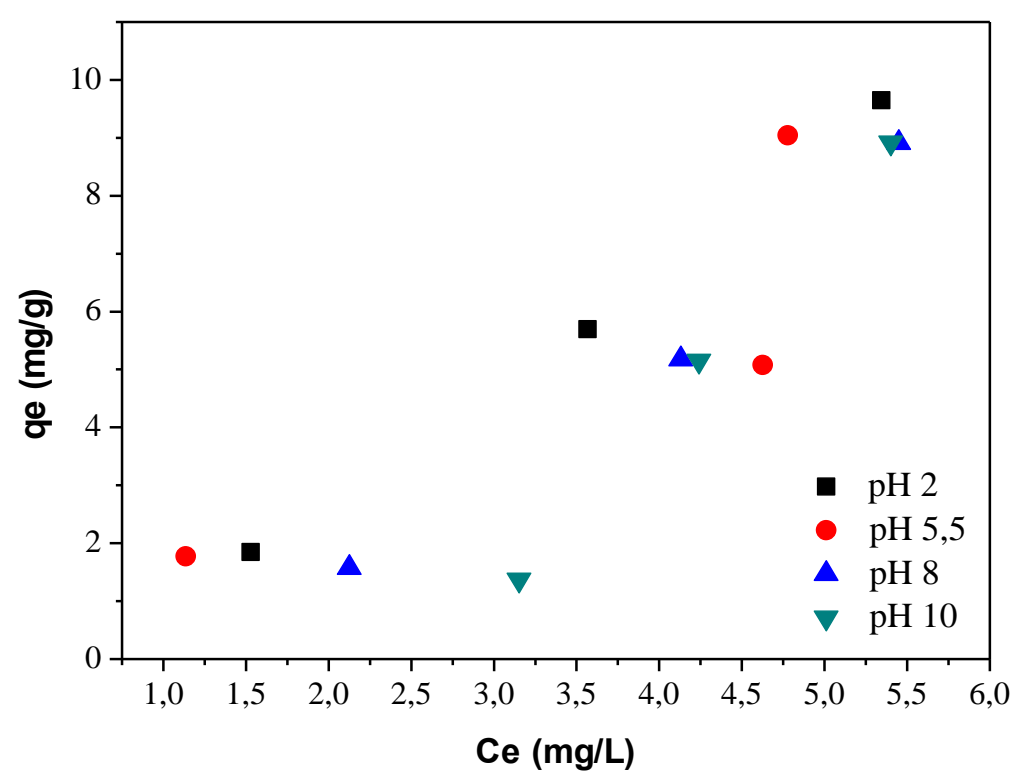

Figura 3.2-Isotermas de adsorção de cromo com variação do $\mathrm{pH}\left(\mathrm{T}=25^{\circ} \mathrm{C}\right.$; [resina

$$
\text { mista }]=5,0 \mathrm{~g} / \mathrm{L}) \text {. }
$$

Neste trabalho, experimentos realizados com o $\mathrm{pH}$ 2,0 foram os que apresentaram melhor resultado, pode-se ressaltar entretanto que a remoção obtida com pH 5,5 foi da 
mesma ordem de grandeza dos testes realizados com $\mathrm{pH} 2,0$, mostrando assim que em valores da região ácida obtém-se bons resultados.

Tabela 3.1- Resultados dos ajustes da Eq.2 (isotermas de adsorção) para o cromo com variação de $\mathrm{pH}$ à temperatura de $25^{\circ} \mathrm{C}$.

\begin{tabular}{cccc}
\hline $\mathrm{pH}$ & $k$ & $\mathrm{R}^{2}$ & Erro \\
\hline 2,0 & 1,742 & 0,983 & 0,10907 \\
5,5 & 1,509 & 0,853 & 0,27715 \\
8,0 & 1,435 & 0,983 & 0,19543 \\
10,0 & 1,354 & 0,997 & 0,23154 \\
\hline
\end{tabular}

\subsection{Teste Cinético e efeito da temperatura}

Os teste cinéticos foram realizados em diferentes concentrações de cromo variando de 10 a $50 \mathrm{mg} / \mathrm{L}$ e diferentes temperaturas $25^{\circ} \mathrm{C}, 35^{\circ} \mathrm{C}$ e $45^{\circ} \mathrm{C}$ que pode ser observado na figura 3.3. Através do teste cinético foi possível determinar que o tempo necessário para que o sistema entre em equilíbrio é de 180 minutos, ao analisar o gráfico tem-se que a quantidade adsorvida do metal torna-se constante a partir do tempo de 60 minutos. O tempo de 180 minutos foi adotado a fim de se garantir que o equilíbrio foi atingido.
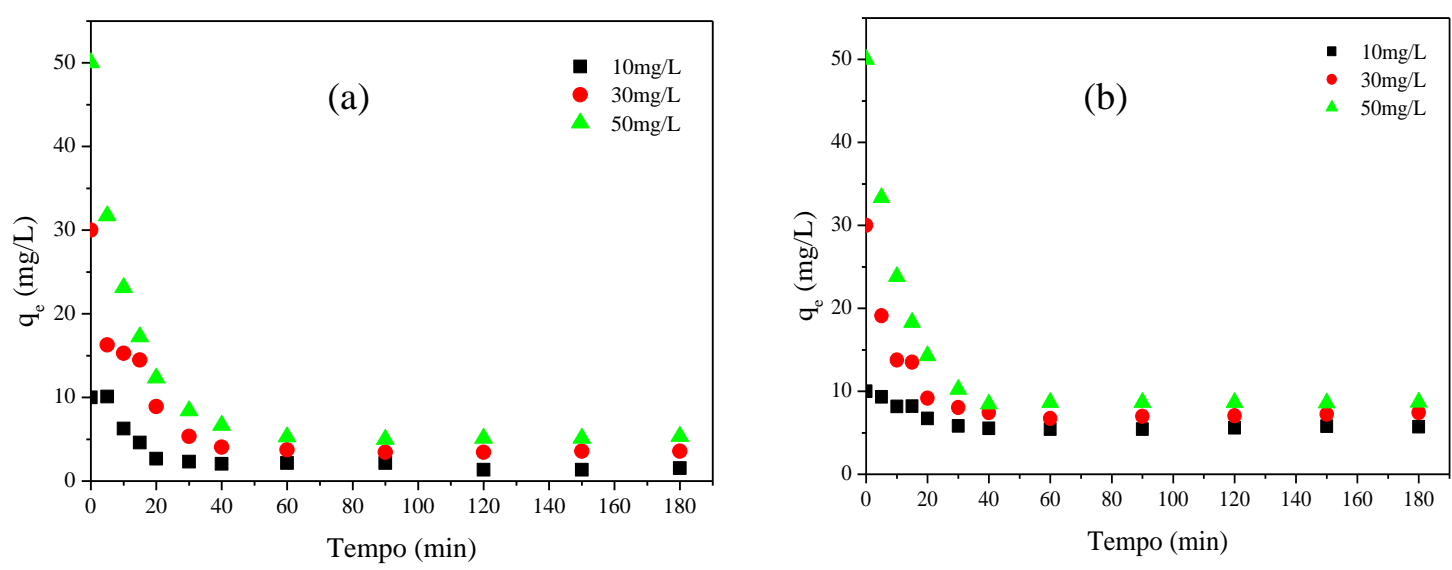

(c) 


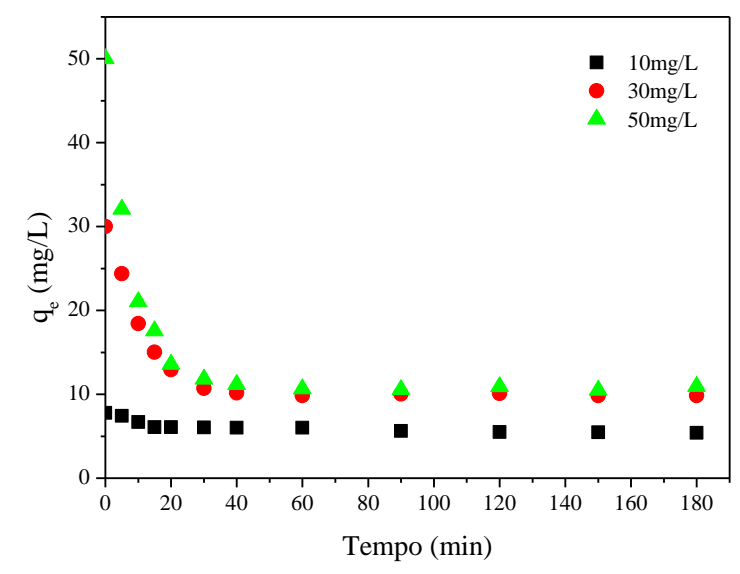

Figura 3.3 - Avaliação cinética da adsorção do cromo em concentrações de 10 a 50mg/L nas temperaturas de $25^{\circ} \mathrm{C}, 35^{\circ} \mathrm{C}$ e $45^{\circ} \mathrm{C}$ : (a) Variação da concentração do íon cromo à temperatura de $25^{\circ} \mathrm{C}$; (b) Variação do íon cromo à temperatura $35^{\circ} \mathrm{C} \mathrm{e} \mathrm{(c)} \mathrm{Variação} \mathrm{da}$ concentração do íon cromo à temperatura de $45^{\circ} \mathrm{C}$.

Pode-se observar que o aumento da temperatura tem influência no processo de adsorção do íon cromo, conforme esperado, já que a temperatura influencia o valor da constante K segunda a lei de Arrhenius (Atkins e Paula, 2008; Fogler, 2008), no qual K representa a interação intermolecular, ou seja, quanto maior a temperatura maior excitação das moléculas e menor interação entre as partículas, justificando assim a temperatura de $25^{\circ} \mathrm{C}$ ser a que apresentou melhores resultados. Como este processo não é favorecido em temperaturas elevadas, a velocidade de adsorção é reduzida com a temperatura.

A partir dos resultados obtidos, foram construídas as isotermas, para o íon cromo, em diferentes temperaturas, apresentadas na Figura 3.4.

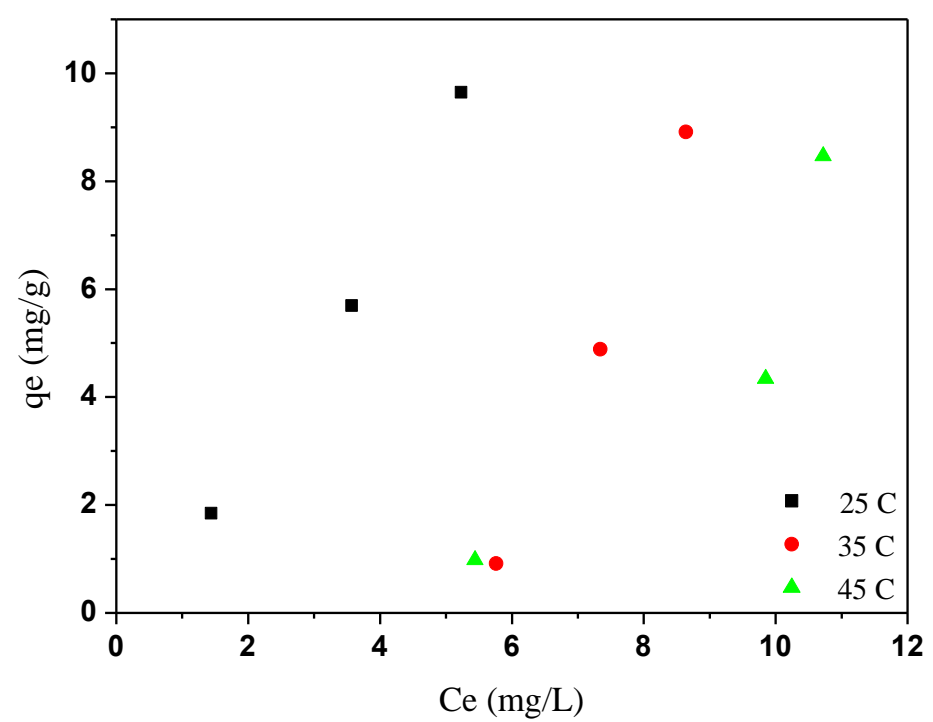

Figura 3.4- Isoterma de adsorção do cromo em temperaturas de $25^{\circ} \mathrm{C}, 35^{\circ} \mathrm{C}$ e $45^{\circ} \mathrm{C}$. 
Analisando as isotermas observou-se que o processo de adsorção do cromo com resina mista tem uma redução na adsorção do íon cromo com o aumento da temperatura. Ademais, entre as temperaturas estudadas, notou-se que a $25^{\circ} \mathrm{C}$ foi a que apresentou os melhores resultados na remoção do íon cromo. $\mathrm{O}$ valor da constante calculada para as temperaturas de $25^{\circ} \mathrm{C}, 35^{\circ} \mathrm{C}$ e $45^{\circ} \mathrm{C}$ como o modelo de Henry e seus respectivos coeficientes de correlação são apresentados na tabela 3.2.

Tabela 3.2- Valores de ajuste do modelo de Henry aos resultados de equilíbrio para adsorção de cromo na faixa de temperaturas $25^{\circ} \mathrm{C}-45^{\circ} \mathrm{C}$.

\begin{tabular}{cccc}
\hline Temperatura & $k$ & $\mathrm{R}^{2}$ & Erro \\
\hline $25^{\circ} \mathrm{C}$ & 1,742048 & 0,983 & 0,10907 \\
$35^{\circ} \mathrm{C}$ & 0,730592 & 0,996 & 0,23496 \\
$45^{\circ} \mathrm{C}$ & 0,575041 & 0,827 & 0,15529 \\
\hline
\end{tabular}

\section{4- AGRADECIMENTOS}

Os autores agradecem à UFU - Universidade Federal de Uberlândia e a FEQUI Faculdade de Engenharia Química pela oportunidade em realizar este trabalho. Agradecem também ao apoio financeiro do CNPq, CAPES e FAPEMIG (processo PCE-00089-14).

\section{5-REFERÊNCIAS}

APHA, AWWA and WPCF, Standard methods for the examination of water and wastewater, 17th ed., American Public Health Association, American Water Works Association and Water Pollution Control Federation, Washington, DC, 1989.

ATKINS, P.; PAULA, J. Físico-Química, Rio de Janeiro: LTC, 2008.

CHUBAR, N., CARVALHO, J.R., NEIVA, M.J. Cork biomass as biosorbent for Cu (II), Zn (II) and Ni(II). Colloids and Surfaces A, v. 230, p. 57-65, 2004.

FOGLER, H. S.; Elementos de engenharia das reações químicas. Rio de Janeiro: LTC, 2008. 
GOOLOKA, M. C.. Toxic and mutagenic effects of chromium (VI): a review. Polyhedron, v.15, p. 3667-3689, 1995.

KAUFAMAN, D. B.. Acute potassium dichromate poisoning in man. American journal of disease of children, v.119, p. 374-381, 1970.

LI, H.; LIU, J.; GAO, X.; LIU, C.; GUO, L.; ZHANG, S.; LIU, X.; LIU, C. Adsorption behavior of indium (III) on modified solvent impregnated resins (MSIRs) containing sec-octylphenoxy acetic acid. Hidrometallurgy. p. 60-67, 2012.

McCABE, W. L.; SMITH, J.; HARRIOT, P. Unit Operations of Chemical Engennering. McGraw Hill International. 2001.

OZDEMIR, G.; OZTURK, T.; CEYHAN, N.; ISLER. R.; COSAR, T. Biosorption of chromium (VI), cadmium (II) and copper (II) by Pantotea sp. TEM18, Chemical Engineering Journal, v.12, p. 249-253, 2004.

PADMAVATHY, V.; VASUDEVAN, B.;DHINGARA, S.C.. Biosorption of nickel (II) ions on Bakers Yeast. Process Biochemistry, v. 38, p. 1389-1395, 2002.

PAL, P.; BANAT, F. Comparison of heavy metal ions removal from industrial lean amine solvent using ion exchange resins and sand coated with chitosan. Journal of Natural Gas Science and Engineering. p. 227-236, 2014

PARK, D. H.; YUN, Y. S.; JO, J. H.; PARK, J. M. Biosorption process for treatment of electroplating wastewater containing $\mathrm{Cr}(\mathrm{VI})$ : laboratory-scale feasibility test. Industrial and Engineering Chemistry Research, v. 45(14), p. 5059-5065, 2006.

SELATNNIA, A.; BAKHIT, M. Z.; MADANI, A,; KERTOUS, L.; MANSOURI, Y.. Biosorption of $\mathrm{Cd}$ (II) from aqueous solutions by $\mathrm{NaOH}$-treated bacterial dead Streptomyces rimosus biomass, Hydrometallurgy, v. 75, p. 11-24, 2004. 